\title{
Functional symptoms in neurology: questions and answers
}

\author{
M Reuber, A J Mitchell, S J Howlett, H L Crimlisk, R A Grünewald
}

J Neurol Neurosurg Psychiatry 2005;76:307-314. doi: 10.1136/jnnp.2004.048280

Between 10 and $30 \%$ of patients seen by neurologists have symptoms for which there is no current pathophysiological explanation. The objective of this review is to answer questions many neurologists have about disorders characterised by unexplained symptoms (functional disorders) by conducting a multidisciplinary review based on published reports and clinical experience. Current concepts explain functional symptoms as resulting from auto-suggestion, innate coping styles, disorders of volition or attention. Predisposing, precipitating, and perpetuating aetiological factors can be identified and contribute to a therapeutic formulation. The sympathetic communication of the diagnosis by the neurologist is important and all patients should be screened for psychiatric or psychological symptoms because up to two thirds have symptomatic psychiatric comorbidity. Treatment programmes are likely to be most successful if there is close collaboration between neurologists, (liaison) psychiatrists, psychologists, and general practitioners. Long term, symptoms persist in over $50 \%$ of patients and many patients remain dependent on financial help from the government. Neurologists can acquire the skills needed to engage patients in psychological treatment but would benefit from closer working relationships with liaison psychiatry or psychology.

See end of article for authors' affiliations

Correspondence to: Markus Reuber, Academic Neurology Unit, University of Sheffield, Royal Hallamshire Hospital Glossop Road, Sheffield S10 2JF, UK: markus.reuber@sth.nhs.uk

Received 25 June 2004 Revised version received 12 October 2004 Accepted 22 October 2004 n a typical neurology outpatient clinic, 10-30\% of patients will have symptoms which are not explicable by demonstrable structural or pathophysiological abnormalities. ${ }^{1}$ Unexplained symptoms are particularly common amongst frequent users of healthcare services. ${ }^{2}$ Up to two thirds of these patients have symptomatic psychiatric comorbidity and many describe suicidal ideation if asked. ${ }^{3}{ }^{4}$ Neurologists need to be able not only to diagnose symptoms as functional but also to communicate with and manage patients in whom no clear organic explanation for symptoms can be found. This article addresses some of the common questions which neurologists face when they see patients with functional symptoms.

\section{WHAT ARE FUNCTIONAL SYMPTOMS?}

Functional symptoms are physical complaints postulated to be associated with psychological distress, which are not primarily explained by pathophysiological or structural abnormalities. This explanation sounds succinct but suffers from several conceptual limitations. Firstly, the diagnosis depends on the exclusion of a medical explanation by clinical judgement or investigation (which may be impossible in paroxysmal disorders like epilepsy, or in conditions like migraine, in which the diagnosis relies on the subjective assessment of the examiner). Secondly, psychological distress is difficult to measure or objectify. Thirdly, functional symptoms can complicate medically explained disease processes which can cause difficulties with delineation and diagnosis.

Functional symptoms can mimic those of most recognised neurological disorders (fig 1), manifest acutely or as a more indolent problem, and can be persistent or intermittent in nature. Functional symptoms can occur together with symptoms of neurologically explained disorders or may be the defining manifestation of a functional disorder.

\section{WHAT NAME SHOULD WE USE FOR FUNCTIONAL SYMPTOMS?}

Functional symptoms have attracted many different terminologies. Some diagnostic labels which were initially acceptable had to be abandoned because they entered common usage as derogatory idioms. ${ }^{5}$ Appropriate terminology is important because the explanation of functional symptoms is an important part of treatment, and the acceptance of the explanation given is associated with a better prognosis. ${ }^{67}$ This communication may be hindered if patients feel that their symptoms are interpreted by the doctor as malingering or exaggeration. A recent study has demonstrated that "functional" is more acceptable to patients than the terms "psychosomatic", "medically unexplained", or "stress related". ${ }^{8}$ In case of seizures, "functional" proved less offensive than "hysterical", "pseudo", "stress related", and "psychogenic" or the expression "non-epileptic attack disorder". 9 The term functional also lends itself to offering patients a positive explanation of symptoms (for example, "there is no damage of nerve cells but a disruption of function").

In the current taxonomies (Diagnostic and Statistical Manual of Mental Disorder, 4th edition (DSM-IV), ${ }^{10}$ International Statistical Classification of Diseases, 10th revision (ICD$10)^{11}$ ) functional symptoms can be classified as manifestations of somatoform disorders (physical symptoms which suggest a general medical condition) or dissociative disorders (disruption

Abbreviations: DSM-IV, Diagnostic and Statistical Manual of Mental Disorder, 4th edition; ICD-10, International Statistical Classification of Diseases, 10th revision 


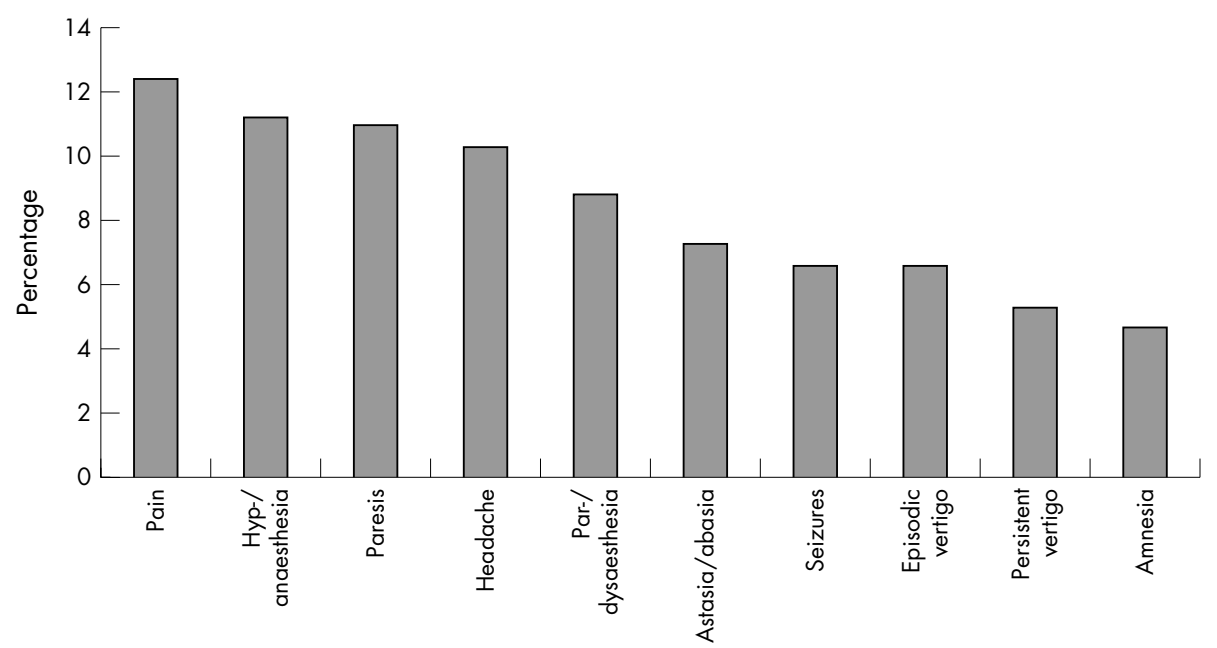

Figure 1 Distribution of 717 functional symptoms in 405 neurology patients. ${ }^{19}$

of the usually integrated functions of consciousness, memory, identity, or perception). However, many functional neurological symptoms (like amnesia or seizures) fulfil diagnostic criteria for both categories. Perhaps because of this, the present clinical criteria in the ICD and DSM systems do not perform well diagnostically if relied upon alone. ${ }^{12}$ What is more, the term "somatoform" does not imply a positive explanation for the symptom, and there have been increasing criticisms of the somatoform classification with more emphasis being placed on symptomatology. ${ }^{13}$

Functional symptoms were previously called "hysterical", but the term's derogatory connotations and the ever widening meaning of the word (for example, mass hysteria, hysterical personality) make it inappropriate. ${ }^{5}$ Functional problems are sometimes called "psychogenic" or attributed to "conversion". However, in the ICD-10 the term "psycho-

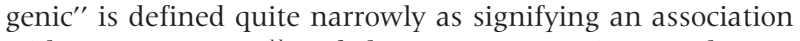
with recent trauma, ${ }^{11}$ and the term "conversion" evokes an aetiological mechanism for which we have no evidence. These models are too simplistic in most cases.

The term "medically unexplained" is a better representation of scientific knowledge to date, but may make patients think that their symptom is not being taken seriously, is unlikely to inspire confidence, and may jeopardise engagement with future therapeutic endeavours.

\section{ARE FUNCTIONAL SYMPTOMS WILFULLY PRODUCED?}

In line with the current classificatory systems of mental disorders (DSM-IV, ICD-10), most clinicians attempt to distinguish between functional symptoms (which are not intentionally produced by the patient) from symptoms that are feigned. However, whereas variability of effort can be quantified, intentionality cannot. ${ }^{14}$ Besides, there may not be a categorical distinction between patients who feign their symptoms and patients who do not. ${ }^{15}$ Because of this, it is actually not possible to say whether or how often functional symptoms are wilfully produced. Fortunately, it is rarely necessary for a clinician to determine whether symptoms are intentional. Even if patients see no other way of reducing psychological distress than feigning illness or exaggerating pathophysiologically explained symptoms, it may be appropriate to offer medical or psychological attention. ${ }^{16}$

\section{ARE THERE CLEAR DISTINCTIONS BETWEEN FUNCTIONAL, FEIGNED, AND HYPOCHONDRIACAL SYMPTOMS?}

The DSM-IV and the ICD-10 encourage clinicians to divide intentional symptoms into malingered symptoms (wilfully produced for external gain) or factitious symptoms (wilfully produced for internal gain). However, it is very difficult for a clinical observer to judge the internal or external reward for a symptom. Similar problems arise with the concept of "secondary gain" (for example, benefits associated with taking on a sick role). ${ }^{17}$

The DSM-IV and ICD-10 further distinguish between somatoform disorders (which are characterised by functional symptoms) and hypochondriasis, in which there is predominant anxiety about illness, often in the presence of misinterpretation of physiological processes in the body. However, somatoform disorders are often also associated with anxiety about "serious" underlying pathology, and this categorical distinction may be difficult to make.

This does not mean that there is no difference between patients whose functional symptoms are unintentional, malingered, factitious, or hypochondriacal. The margins between these conditions are simply not as clear as the prototypical definitions in the DSM-IV and ICD-10 suggest.

\section{ARE FUNCTIONAL SYMPTOMS DISPROPORTIONATELY PREVALENT IN NEUROLOGY?}

Although many who have written about functional symptoms (Thomas Willis, Jean-Martin Charcot, Joseph Babinski, Sigmund Freud, to name but a few) had a neurological background, a comparative study found that functional symptoms were similarly prevalent in other medical specialties. ${ }^{18}$ Within neurology, one study found that $9 \%$ of 4470 inpatient episodes were provoked by psychogenic disorders, ${ }^{19}$ and a second reported that $11 \%$ of 300 consecutive neurological outpatient presentations were "not at all explained" by organic disease, 19\% "somewhat explained", $27 \%$ "largely explained", and $43 \%$ "completely explained". ${ }^{1}$ Several reports suggest that the risk of functional symptoms is increased in patients with physical disorders of the brain, or indeed the peripheral nervous system, ${ }^{20-22}$ but (perhaps because of the indistinct conceptual boundaries) the prevalence of functional symptoms in the context of structural or pathophysiologically explained neurological disorders is unknown. 


\section{WHAT CAUSES FUNCTIONAL SYMPTOMS?}

Recent attempts to explain functional symptoms have focussed on volition, ${ }^{23}$ attention, ${ }^{24}$ and auto-suggestion. ${ }^{25}$ One attractive model suggests that somatisation represents an innate coping mechanism learned from early parent-child interactions. ${ }^{26}{ }^{27}$ The neurobiological substrate of functional symptoms remains elusive, but it is now clear that the brain can physically adapt to environmental challenges and stress, ${ }^{28} 29$ so scientific understanding has moved beyond the dualistic concept of separation between mind and brain. Functional or voxel based neuroimaging techniques may bridge the gap between theoretical concepts and biological understanding in the future. However, whilst the studies completed to date are promising, they have been small and their results are difficult to interpret. ${ }^{30-33}$

In the absence of a clear pathophysiological understanding, patients with functional neurological symptoms are perhaps best understood using a multidimensional aetiological model, in line with that proposed for other unexplained somatic disorders. ${ }^{34}$ This approach can accommodate biographical factors (like childhood trauma, abuse, life events), relevant biological features (like gender), psychological features (like poor coping styles, the tendency to dissociate, emotional expressiveness), neurological co-morbidity (for example learning disability or epilepsy), social aspects (such as a disturbed family environment, financial insecurity, absence of friends or confidants, limited coping resources), and broader cultural factors (such as attitudes to illness, gender roles). The biopsychosocial model of disease developed in the 1980s, which considers the interplay between all these factors, is a helpful conceptual approach in this context. ${ }^{35}$

The analysis of an individual patient can be informed by a pragmatic distinction between predisposing factors (conferring an increased vulnerability to functional symptoms), precipitating factors (triggering symptoms), and perpetuating factors (contributing to a chronically recurrent course). ${ }^{36}$ These factors interact with other psychiatric disorders (like anxiety disorders, posttraumatic stress disorder, depression) and personality traits (especially those typical of borderline and dependent personality disorders). ${ }^{37}$ The importance of the various factors differs substantially between patients and may even change in the same patient over time. In assessing the importance of possible aetiological factors it is important to note that the presence of one particular factor (for instance childhood abuse) does not automatically make it aetiologically relevant.

In many patients a history of trauma, a stressful life event, or an "unspeakable dilemma" can be identified. ${ }^{38}{ }^{39}$ Often functional disorders seem to be sparked off by a relatively small event which appears to serve as a symbolic reminder of more serious trauma or distress in the past. ${ }^{40}$ Even if the identified problem does not seem serious enough to trigger a disabling functional symptom, it may be useful in engaging patients in psychological treatment.

\section{HOW CAN WE DIAGNOSE FUNCTIONAL SYMPTOMS?}

The first step in the diagnosis of functional symptoms is the exclusion of a neurologically explained problem. Clinicians have to strike a balance between the pursuit of diagnostic certainty and the fact that continuing investigations may not allow patients to address psychosocial issues and have the potential to cause anxiety and iatrogenic damage. The second, equally important step is the screen for aetiologically relevant psychological or psychiatric features. These are likely to be serious recent life events, but triggers could be more subtle in patients with pre-existing inadequate coping skills. This stress-diathesis model means that explicit psychological criteria for the diagnosis of functional disorder remain elusive although some recent progress has been made. ${ }^{41}$

The clinical signs of functional weakness and sensory disturbance, ${ }^{42}$ disorders of gait or stance, ${ }^{42-44}$ and nonepileptic seizures ${ }^{45}{ }^{46}$ have been described in detail elsewhere (table 1).

Of course, the clinical tests or investigations which are required to exclude neurological disorders differ between one symptom and another. Before asking for tests clinicians should attempt to review their patient's previous health records to avoid needless replication. What is more, thick notes with presentations to many different specialities can also act as a diagnostic pointer. ${ }^{47}$ When requesting investigations clinicians should consider that tests with a low pretest probability of detecting pathology are associated with a high risk of false positive results. Many tests rely on the detection of inconsistency of the clinical problem (apparent in collapsing weakness or the inability to lift a leg off an examination couch whilst being able to walk). Inconsistency also becomes apparent when the quantitatively poor performance of patients with functional disorders in neuropsychological tests is analysed in a qualitative manner. ${ }^{48}{ }^{49}$ In patients with apparent weakness or sensory loss, inconsistency can also be found by demonstrating intact sensory pathways using neurophysiological methods like evoked potentials. ${ }^{50} 51$

Of course, the detection of inconsistency simply raises the possibility that a conventional syndrome does not fit-it does not follow that a functional disorder must be present. Patients with many neurologically explained disorders show marked diurnal variation or variable symptoms.

\section{HOW CERTAIN CAN WE BE THAT A SYMPTOM IS FUNCTIONAL?}

Several recent studies have shown that patients whose symptoms are considered neurologically unexplained after appropriate assessment rarely turn out to be diagnosed with a somatic neurological disorder later. However, it should be born in mind that these studies were carried out at specialist

Table 1 Clinical signs associated with functional neurological symptoms ${ }^{42-46}$

\begin{tabular}{ll}
\hline Symptom & Clinical sign or observation \\
\hline Paralysis & Variable loss of function \\
& Hoover's sign \\
& Collapsing weakness \\
lpsilateral sternocleidomastoid weakness & Lack of ipsilateral facial weakness \\
& Weakness with normal tone and reflexes \\
Gait and stance & Fluctuating nature \\
& Dragging of inverted or everted foot \\
& Excessively slow movement \\
& Romberg's test with patient falling towards \\
& examiner regardless of position of examiner \\
& Walking as if on ice \\
& Uneconomical gait \\
& Giving way of legs with prevention of fall \\
& Whole limb anaesthesia \\
Hemisensory loss for all modalities to midline & Precipitated by stressful situation \\
Sensory & Duration $>2$ min, tendency to present as seizure \\
& status \\
& Waxing and waning of motor activity or \\
prolonged limp unresponsiveness & Side to side head movements \\
& Pelvic thrusting \\
Ictal or immediately postictal crying \\
Partial responsiveness during seizures \\
Closed eyes, resistance to eye opening \\
Unexpectedly rapid or slow recovery \\
\hline
\end{tabular}


centres, and that the risk of a misdiagnosis of disorders characterised by functional symptoms may be higher in less well investigated patients. Stone et al found that a neurological explanation had been found in one of 42 patients with functional weakness or sensory loss after a mean of 12.5 years of follow up. ${ }^{52}$ Crimlisk et al found that only three of 64 patients with functional weakness had developed an identifiable somatic disorder explaining the weakness 6 years after the initial assessment (two out of these three patients were misdiagnosed because they had disorders with variable symptoms). ${ }^{53}$ Couprie et al found an unexpected somatic explanation in four of 56 patients with a functional neurological problem after $1.5-9.5$ years. ${ }^{54}$

Although it therefore seems that the finding that a symptom is functional usually stands the test of time, physicians have a tendency to underdiagnose functional problems. ${ }^{55}$ This is likely to be one of the reasons why patients with non-epileptic seizures for instance are often misdiagnosed as having epilepsy for many years ${ }^{56}$ (fig 2). Several studies have shown that the delay in the diagnosis of functional symptoms is associated with poorer outcome. ${ }^{53} 5758$ Patients do therefore not benefit from a delayed diagnosis but may suffer as a result of it. The misdiagnosis of non-epileptic seizures as epilepsy is particularly dangerous-severe iatrogenic injury, pregnancy loss, and death have been reported..$^{59-61}$ Physicians who fail to identify medically unexplained disorders may be faced with litigation. ${ }^{62}$

This does not mean that neurologists should rush into calling a symptom functional. There are also risks of overdiagnosing functional problems. ${ }^{63}{ }^{64}$ In particular, patients with atypical or rare organic disease presentations may not receive appropriate treatment or be denied financial help for incapacity from the government. ${ }^{65}$ Once a clinician has diagnosed a problem as functional, patients are less likely to be taken seriously by colleagues or to receive palliative or curative treatment. ${ }^{66}$

In the absence of a diagnostic gold standard, a degree of doubt about a neurologically explained disorder may remain. However, clinicians can usually be sure enough of the functional nature of a symptom to stimulate a search for possible (psychosocial) triggers and associated psychopathology, and to propose psychological forms of treatment.

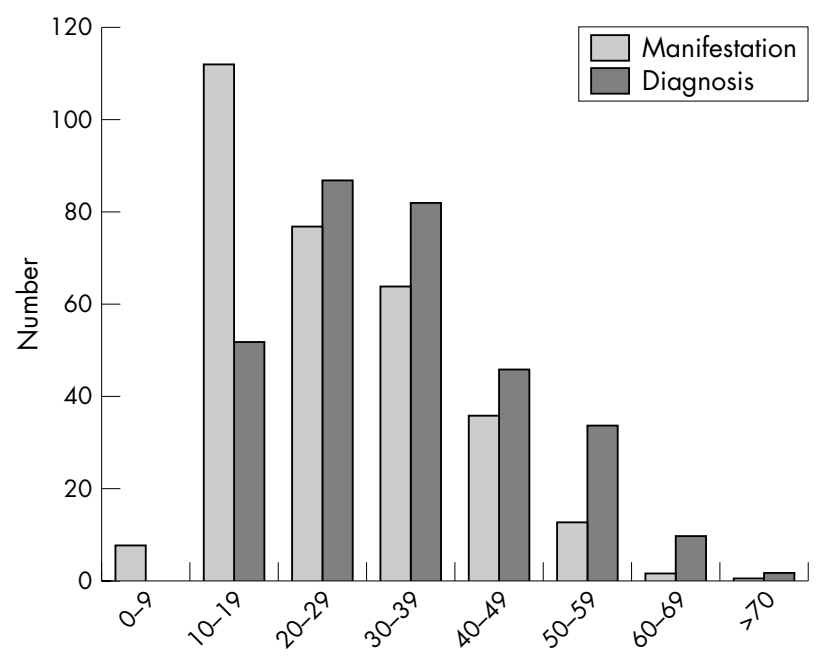

Figure 2 Age at seizure manifestation and correct diagnosis of 313 patients with non-epileptic seizures. Almost all patients were thought to have epilepsy and $75.5 \%$ had been treated with anticonvulsant drugs. ${ }^{56}$
WHAT IS THE BEST WAY OF COMMUNICATING THE DIAGNOSIS OF A FUNCTIONAL PROBLEM?

The basic communication skills required for patients with functional symptoms do not differ from those which are helpful with other patients. ${ }^{67}{ }^{68}$ If the initial communication goes well, symptoms settle in a substantial group of patients. ${ }^{69} 70$ Communication is more likely to be successful if positive diagnostic factors (significant life events, psychiatric features) and negative factors (inconsistencies, negative investigations) have been elicited so that the relevance of psychological factors becomes more believable to the patient. ${ }^{71}$ A good way to begin is to enquire what the patient's particular concerns about his symptom are, and what he may have been told by other doctors, so that specific reassurance can be given.

The initial explanation should cover the items listed in table 2. The aims of this conversation include reducing anxiety, instilling a degree of therapeutic optimism, and facilitating engagement in further psychological therapy. Outcome is likely to be better if a positive diagnosis is made (for example, "you have (a) functional weakness/numbness/ seizures"), and this diagnosis is explained as much as this is possible (for example, "we are not entirely sure what causes functional weakness/numbness/seizures, but we often see them in patients who are under a lot of stress/who have suffered a loss/who have been badly upset by something..."). ${ }^{72}$ The physician may pause at this point of the explanation to give the patient a chance to volunteer a relevant traumatic event, conflict, or problem. At no point should the patient be made to feel coerced into making a disclosure, and it should be made clear that the patient should do this only at a time and place with which they feel comfortable. Patients may be probed gently ("I wonder if you recognise any of this in your own life?").

The possible co-occurrence of physical and psychological symptoms should be discussed if applicable (stressing that any separation is quite artificial). It may be helpful to include an educational element at this point to help the patient to understand how emotional factors could be causing physical symptoms. This is best given as a three stage explanation, linking mood, pathogenesis, and symptoms (for example, "When people are anxious the muscles in their neck tend to tense up and that can cause headaches"'). ${ }^{73}$

Finally, the neurologist should explain the plan for further management. If symptoms are acute, patients may improve with an explanation, encouragement, positive suggestion, and physiotherapy. In more chronic cases, and to anticipate and prevent relapse, a psychological approach should be considered and offered in most cases.

Neurologists will need to make themselves aware of local pathways of referral for psychological treatment. Ideally this should be closely integrated into the neurological diagnostic and therapy service. Finding a suitable therapist may not be easy because there is little evidence that the provision of psychotherapy services in the National Health Service has improved much since it was last investigated in $1996 .{ }^{74}$

The practice of copying medical correspondence to patients (which has been endorsed by recent government policy in the UK) offers a further opportunity to enforce the points which were made during the consultation. The effects of this practice have not been studied in the context of functional symptoms, but they have been studied in psychiatric practice. ${ }^{75}$ Results show that there are many reasons why openness could be particularly helpful in this context. Of course, copied letters will cause offence and confusion if they do not reflect the discussion during the consultation. 
Table 2 Management of patients with functional neurological symptoms

\begin{tabular}{|c|c|c|}
\hline Management stage & Suggested approach & References and further reading \\
\hline Initial assessment & $\begin{array}{l}\text { Demonstrate that you believe and are interested in symptom and severity } \\
\text { Elicit history of other symptoms, previous contacts with health service } \\
\text { Find out what patient has been told about his symptom by other doctors } \\
\text { Elicit patient's own beliefs about the symptom } \\
\text { Screen for significant psychiatric disorder (especially depression and anxiety) } \\
\text { Show interest in impact of symptoms on patients' life } \\
\text { Ask about life events } \\
\text { Obtain history from partner/relative/friend if possible } \\
\text { Review previous clinical records if possible } \\
\text { Arrange appropriate tests (if necessary) }\end{array}$ & $\begin{array}{l}\text { Craig, }^{40} \text { Williams and House, } \\
\text { Page and Wessely }{ }^{47} \\
\text { Creed and Guthrie, } \\
\text { Fink et al, }{ }^{106} \\
\text { Morriss et al }{ }^{108}\end{array}$ \\
\hline Communication of diagnosis & $\begin{array}{l}\text { Admit uncertainty if investigations incomplete/inconclusive } \\
\text { Clarify with the patient how structural disease has been excluded } \\
\text { (taking account of patient's specific health concerns) } \\
\text { Reframe symptoms ("I can see that since you lost your wife....") } \\
\text { Give a positive explanation of the symptom } \\
\text { Convey the potential for substantial recovery } \\
\text { Be honest and direct with patents (copying clinic letters is a good } \\
\text { way of reiterating important issues) }\end{array}$ & $\begin{array}{l}\text { Page and Wessely, }{ }^{67} \\
\text { Jackson and Kroenke, } \\
\text { Morriss et al, } \\
\text { Coia and Morley }\end{array}$ \\
\hline Acute symptomatic therapy & $\begin{array}{l}\text { Discuss potential acute/remote stressors } \\
\text { Suggest that symptoms are likely to improve } \\
\text { Encourage activity rather than rest/consider physiotherapy }\end{array}$ & Richardson and Engel ${ }^{114}$ \\
\hline Psychiatric medication & $\begin{array}{l}\text { Ask the patient's view (will they take the tablets?) } \\
\text { Consider antidepressants even in the absence of overt } \\
\text { depressive/anxiety symptoms } \\
\text { Explain length of treatment, possibly delayed effectiveness, } \\
\text { lack of addictive potential }\end{array}$ & $\begin{array}{l}\text { O'Malley et al, }{ }_{1}^{98} \text { Soloff,, } \\
\text { Stone et al }{ }^{102}\end{array}$ \\
\hline $\begin{array}{l}\text { Referral for psychological/ } \\
\text { psychiatric assessment }\end{array}$ & $\begin{array}{l}\text { Point out that reducing stress and learning ways of coping with symptoms } \\
\text { are useful to all patients regardless of the nature of their symptoms } \\
\text { Consider joint appointment } \\
\text { Be optimistic but avoid raising expectations to levels } \\
\text { which are likely to disappoint }\end{array}$ & House $^{115}$ \\
\hline $\begin{array}{l}\text { Psychological management } \\
\text { options }\end{array}$ & $\begin{array}{l}\text { Consider patient held treatment plan, or patient held records } \\
\text { Identify goals for treatment } \\
\text { Work on identifying predisposing, precipitating, and perpetuating factors } \\
\text { Look at potentially problematic patterns in interpersonal relationships } \\
\text { Identify ongoing life stressors } \\
\text { Identify and address patterns reinforcing abnormal behaviour } \\
\text { Reframe and reatribute the links between psychological factors and symptoms } \\
\text { Consider the use of specific psychotherapeutic techniques by those } \\
\text { with appropriate training (for example, cognitive behavioural and } \\
\text { analytical, interpersonal, behavioural psychotherapy) } \\
\text { Use appropriate evidence based psychological interventions } \\
\text { to treat anxiety and depression if present } \\
\text { Discuss relapse prevention } \\
\text { Consider goodbye letter to patients on completion of work } \\
\text { reinforcing issues discussed and recording progress made. }\end{array}$ & $\begin{array}{l}\text { Goldberg et al }{ }^{73} \text { Guthrie, }^{85} \\
\text { Bleichhardt et al, } \\
\text { Sharpe et al, }{ }^{96} \\
\text { Roth and Fonagy, } \\
\text { Fink et al }{ }_{1}^{106} \\
\text { Morriss et al }{ }^{108}\end{array}$ \\
\hline
\end{tabular}

\section{SHOULD PATIENTS WITH FUNCTIONAL SYMPTOMS BE REFERRED TO A PSYCHIATRIST?}

Many neurologists are uncomfortable continuing to see patients with functional symptoms. As a consequence, they may get little opportunity to improve their clinical practice in this area. Adult psychiatric services have had to focus on so called severe mental illness (that is, bipolar disorder and schizophrenia), and psychiatrists may therefore also have limited expertise in dealing with these problems. The fact physicians seem unable to address their problem is one of the reasons why many patients with unexplained symptoms keep seeking medical advice. ${ }^{2}$

Ideally, patients with a functional neurological symptoms should be screened for anxiety and depression and should be offered a psychological and psychiatric assessment. Whilst functional disorders do not sit easily within a categorical diagnostic system (see above), there is general agreement that they are a important marker of psychiatric morbidity. ${ }^{76}$ In one study of 300 consecutive new patients seen in a neurological outpatient clinic, $67 \%$ of patients with unexplained symptoms but only $38 \%$ of patients with explained symptoms had depressive or anxiety disorders. ${ }^{3}$ In another study, 33\% of patients with functional motor symptoms but only $10 \%$ of patients in the control group had a major psychiatric disorder. ${ }^{77}$ Whereas $13 \%$ of patients with unexplained symptoms had seriously considered suicide in the last 2 weeks, only $7 \%$ of patients with explained symptoms had done so. ${ }^{4}$ These results fit with the observations in other areas of medicine that patients with unexplained symptoms are roughly twice as likely to suffer from psychiatric disorders. ${ }^{78}$ Patients with more unexplained symptoms are at greater risk..$^{79} 80$

Ideally the psychiatric assessment should be carried out by a psychiatrist with an interest in this area (or by a neurologist with relevant psychiatric skills). Unfortunately, liaison psychiatry services (and neurological services for patients with functional disorders) remain patchy and a substantial group of patients will decline the option of seeing a psychiatrist. $^{3}$ To some patients, a psychologist may be a more acceptable option (especially if they are part of the neurological team). Good communication between different disciplines is essential to avoid patients being given mixed or confusing messages.

\section{WHAT SPECIALIST TREATMENT IS AVAILABLE?}

There are insufficient randomised controlled trials in the area of functional neurological symptoms. Evidence from the treatment of other medically unexplained symptoms and similar disorders, however, supports the hypothesis that psychotherapeutic methods may be helpful in some 
patients. ${ }^{81-86}$ The evidence is perhaps strongest for variants of cognitive behavioural therapy. ${ }^{87-89}$ Psychodynamic, interpersonal therapy, and hypnosis have been shown to be effective treatments for irritable bowel syndrome, ${ }^{90-92}$ a disorder often comorbid with functional neurological symptoms. ${ }^{93}$ Furthermore, biofeedback methods may be useful in the treatment of somatoform disorders. ${ }^{94}$

Little is known about which patients benefit most from which approach. Predisposing and precipitating factors are important in building up an understanding of the patient. However, the mere disclosure of traumatic factors alone is usually not sufficient. ${ }^{95}$ Therapy needs to focus especially on factors perpetuating symptoms if it is to be of lasting benefit. ${ }^{96}$ It is important to note that the kind of psychotherapy required is not the same as counselling (schooled listening) which is only likely to help in milder (or self limiting) psychiatric disorders. ${ }^{97}$

Antidepressants may be useful in the treatment of patients with functional symptoms. They may even be effective for those without a depressive syndrome. ${ }^{98}$ Antidepressants have been shown to reduce emotional dysregulation, ${ }^{99}$ a personality trait associated with functional symptoms. ${ }^{100}$ One of the most common reasons for non-response to antidepressants is an inadequate dose given for an inadequate length of time. ${ }^{101}$ Neurologists should anticipate that nearly three quarters of neurological outpatients think antidepressants are addictive, and nearly half think they can do physical harm. ${ }^{102}$ Patients who can see the reasons for taking medication are more likely to complete the course.

Antipsychotic drugs may have a very limited role in the treatment of patients with quasi-psychotic dissociative symptoms resistant to other methods but should be used with caution because of long term side effects. ${ }^{103}$

\section{DO NEUROLOGISTS NEED TO FOLLOW UP ALL THEIR PATIENTS WITH FUNCTIONAL SYMPTOMS?}

Rapid discharge from a neurological clinic may be interpreted by the patient as a sign that the neurologist disbelieves him or her. They may then be forced to rely on financial help from the government, or are left dependent on their family or social support network (we know that patients with nonepileptic attacks are more likely to receive financial help from the government than comparable patients with epileptic seizures $\left.{ }^{104}{ }^{105}\right)$. It is often wise to oversee any transfer of clinical care to psychological or psychiatric services as many patients do not engage easily.

Follow up should satisfy a number of aims: (1) to signal to the patient that his complaint is being taken seriously without the need for a further health crisis; (2) to facilitate engagement in a psychological treatment programme; (3) to reduce the risk of referral for a more palatable specialist opinion; (4) to offer the opportunity to review the diagnosis and ensure no alternative pathology has been missed (especially if new symptoms evolve); and (5) to avoid inappropriate diagnostic re-assignment to an organic disorder.

In practice, only a small number of patients with mixed physical and psychological disorders (for instance epilepsy and non-epileptic seizures) will require long term follow up by a neurologist. For patients with chronic medically unexplained symptoms who fail to improve with a psychological treatment programme the focus may shift to the maintenance of social functioning and minimisation of iatrogenic damage. Programmes for the effective management of such patients in primary care emphasise the regular assessment of patients by a single, identified health practitioner to pre-empt crisis generation, the withdrawal of unnecessary medication and specialist referrals, and the setting of achievable goals (damage limitation rather than cure). ${ }^{106}$ As a minimum these programmes can reduce healthcare usage and cost. ${ }^{107}$ Some patients may also be open to a process of reattribution. One influential approach to reattribution is based on the three stage process of making the patient feel understood, changing the agenda from a focus on symptoms to a wider view of abilities, and relating symptoms to psychosocial problems. ${ }^{73} 108$

\section{WHAT IS THE PROGNOSIS OF FUNCTIONAL NEUROLOGICAL SYMPTOMS?}

Studies of patients with functional paresis or sensory disturbance show that $37-83 \%$ of patients (mean age 3639 years) continued to have symptoms 2-16 years after diagnosis. ${ }^{52-54} 58109$ The study with the longest follow up showed that $29 \%$ of patients had retired on medical grounds. ${ }^{52}$ Outcome was similarly poor in unselected neurological outpatients with medically unexplained symptoms. Symptoms were worse or persisted in $54 \%$ of patients 8 months after the original assessment. ${ }^{110}$ The prognosis appears even worse in patients with non-epileptic seizures. The largest study showed that $71 \%$ of patients continued to have seizures 11 years after manifestation, and 56\% of patients were dependent on social security. ${ }^{111}$ Patients who remain unimproved continue to consume healthcare resources. One follow up study of 64 patients with motor conversion symptoms diagnosed at a tertiary neurology referral centre found that 6 years after diagnosis $51 \%$ of patients had been re-referred to another neurologist $(28 \%$ with the same symptom). ${ }^{112}$

There is a danger that new clinicians unfamiliar with a case will relaunch unnecessary investigations or diagnose organic disease which has previously been ruled out. The investigation of the outcome of patients with non-epileptic seizures found that despite advice to discontinue them, $41 \%$ of patients were still taking anticonvulsants 5 years later. ${ }^{111}$

Even with psychological treatment, outcome is not good in all patients. A long history of physical symptoms, particularly debilitating symptoms and entrenched support systems which reinforce illness behaviour, predict a poor prognosis. The prognosis is better if patients acknowledge emotional distress in relation to their symptoms and in patients with adequate support who live in a stable social environment. Poor compliance or an unwillingness to engage are likely to result in poor outcome. ${ }^{85}$

\section{CONCLUSION}

Functional neurological symptoms are common but poorly understood and frequently mismanaged. After appropriate investigations, clinicians should not be afraid of calling symptoms functional. However, there is a risk of both under and over diagnosis. When neurologists do not follow up such patients themselves diagnostic errors may be perpetuated. The outcome of disorders characterised by functional neurological symptoms is currently poor. Outcomes are likely to improve if the diagnosis of such disorders was sought more actively and communicated more successfully. Whilst many questions about nosology, aetiology, and long term effectiveness of treatment remain open, it is not appropriate to refuse treatment to patients with the biological potential to make a full recovery. Neurologists are well placed to work in collaboration with (liason) psychiatrists, psychologists, and general practitioners to develop treatment programmes for patients with functional neurological symptoms.

\section{Authors' affiliations}

M Reuber, Academic Neurology Unit, University of Sheffield, Royal Hallamshire Hospital, Glossop Road, Sheffield S10 2JF, UK

A J Mitchell, Department of Liaison Psychiatry, Brandon Mental Health Unit, Leicester General Hospital, Gwendolen Road, Leicester LE5 4PW, UK 
S J Howlett, R A Grünewald, Department of Neurology, Royal Hallamshire Hospital, Glossop Road, Sheffield, UK

H L Crimlisk, Department of Liaison Psychiatry, Sheffield Care Trust, Longley Centre, Norwood Grange Drive, Sheffield S5 7JT, UK

Competing interests: none declared

\section{REFERENCES}

1 Carson AJ, Ringbauer B, Stone J, et al. Do medically unexplained symptoms matter? A prospective cohort study of 300 new referrals to neurology outpatients. J Neurol Neurosurg Psychiatry 2000;68:207-10.

2 Reid S, Wessely S, Crayford T, et al. Frequent attenders with medically unexplained symptoms: service use and costs in secondary care. Br J Psychiatry 2002;180:248-53.

3 Carson AJ, Ringbauer B, MacKenzie L, et al. Neurological disease, emotional disorder, and disability: they are related: a study of 300 consecutive new referrals to a neurology outpatient department. J Neurol Neurosurg Psychiatry 2000;68:202-6.

4 Carson AJ, Best S, Warlow C, et al. Suicidal ideation among outpatients at general neurology clinics: an outpatient study. BMJ 2000;320:1311-2.

5 Crimlisk HL, Ron MA. Conversion hysteria: history, diagnostic issues, and clinical practice. Cogn Neuropsychiatry 1999:4:165-80.

6 Carton S, Thompson PJ, Duncan JS. Non-epileptic seizures: patients' understanding and reaction to the diagnosis and impact on outcome. Seizure 2003;12:287-94.

7 Ettinger AB, Devinsky O, Weisbrot DM, et al. A comprehensive profile of clinical, psychiatric, and psychosocial characteristics of patients with psychogenic nonepileptic seizures. Epilepsia 1999:40:1292-8.

8 Stone J, Woicik W, Durrance D, et al. What should we say to patients with symptoms not explained by disease? The "number needed to offend". BMJ 2003:325:1449-50.

9 Stone J, Campbell K, Sharma N, et al. What should we call pseudoseizures? The patient's perspective. Seizure 2003;12:568-72.

10 American Psychiatric Association. Diagnostic and statistical manual of mental disorders. Washington, DC: APA, 1994

11 World Health Organization. The ICD-10 Classification of Mental and Behavioural Disorders: Clinical Descriptions and Diagnostic Guidelines. Geneva: WHO, 1992.

12 Rief W, Hiller W. Toward empirically based criteria for the classification of somatoform disorders. J Psychosom Res 1999;46:507-18.

13 Sharpe M, Mayou R. Somatoform disorders: a help or a hindrance to good patient care? Br J Psychiatry 2004; 184:470-6.

14 Halligan P, Bass C, Oakley DA. Wilful deception as illness behaviour. In: Halligan P, Bass C, Oakley DA, eds. Malingering and illness deception. Oxford: Oxford University Press, 2003:3-28

15 Fink $\mathbf{P}$. Physical complaints and symptoms of somatizing patients. J Psychosom Res 1992;36:125-36.

16 Miller E. Conversion hysteria: is it a viable concept. Cogn Neuropsychiatry 1999:4:181-91.

17 Bordini EJ, Chaknis MM, Ekman-Turner RM, et al. Advances and issues in the diagnostic differential of malingering versus brain injury. Neurorehabilitation 2002;17:93-104.

18 Nimnuan C, Hotopf $M$, Wessely S. Medically unexplained symptoms: an epidemiological study in seven specialities. J Psychosom Res 2001;51:361-7.

19 Lempert T, Dieterich M, Huppert D, et al. Psychogenic disorders in neurology: frequency and clinical spectrum. Acta Neurol Scand 1990:82:335-40.

20 Reuber M, Fernández G, Helmstaedter C, et al. Are there physical risk factors for psychogenic nonepileptic seizures in patients with epilepsy? Seizure 2003;12:561-7.

21 Caplan LR, Nadelson T. Multiple sclerosis and hysteria. Lessons learned from their association. JAMA 1980;243:2418-21.

22 Merskey H, Trimble M. Personality, sexual adjustment, and brain lesions in patients with conversion syndromes. Am J Psychiatry 1979;136:179-82.

23 Spence SA. Disorders of willed action. In: Halligan PW, Bass C, Marshall JC, eds. Contemporary approaches to the study of hysteria. Oxford: Oxford University Press, 2001:235-50.

24 Sierra M, Berrios GE. Towards a neuropsychiatry of conversion hysteria Cogn Neuropsychiatry 1999;4:267-87.

25 Oakley DA. Hypnosis and conversion hysteria: a unifying model. Cogn Neuropsychiatry 1999:4:243-65.

26 Muris P, Meesters C. Children's somatization symptoms: correlation with trait anxiety, anxiety sensitivity and learning experience. Psychol Rep 2004;94:1269-75.

27 Salmon P, Al-Marzoogi SM, Baker G, et al. Childhood family dysfunction and associated abuse in patients with nonepileptic seizures: towards a causal model. Psychosom Med 2003;65:695-700.

28 Yamasue H, Kasai K, Iwanami A, et al. Voxel-based analysis of MRI reveals anterior cingulate gray-matter volume reduction in posttraumatic stress disorder due to terrorism. Proc Natl Acad Sci U S A 2003;100:9039-43.

29 Bremner JD, Vythilingam M, Vermetten SM, et al. MRI and PET study of deficits in hippocampal structure and function in women with childhood sexual abuse and posttraumatic stress disorder. Am J Psychiatry 2003; 160:924-32.

30 Ron MA. Explaining the unexplained: understanding hysteria. Brain 2001;124:1065-6.

31 Vuilleumier $\mathbf{P}$, Chicherio $\mathrm{C}$, Assal $\mathrm{F}$, et al. Functional neuroanatomical correlates of hysterical sensorimotor loss. Brain 2002;124:1077-90.
32 Spence SA, Crimlisk HL, Cope H, et al. Discrete neurophysiological correlates in prefrontal cortex during hysterical and feigned disorder of movement. Lancet 2000;355:1243-4

33 Marshall JC, Halligan PW, Fink GR, et al. The functional anatomy of a hysterical paralysis. Cognition 1997;64:B1-8.

34 Wessely S, Nimnuan C, Sharpe M. Functional somatic syndromes: one or many. Lancet 1999;354:936-9.

35 Taylor GJ. Psychosomatic medicine and contemporary psychoanalysis. Madison, CT: IUP, 1987.

36 Sharpe M. Medically unexplained symptoms and syndromes. Clin Med 2002;2:501-4.

37 Reuber M, Pukrop R, Derfuss R, et al. Multidimensional assessment of personality in patients with psychogenic nonepileptic seizures. I Neurol Neurosurgery Psychiatry 2003;75:743-8.

38 Roelofs K, Keijsers GPJ, Hoogduin CAL, et al. Childhood abuse in patients with conversion disorder. Am J Psychiatry 2002;159:1980-13.

39 Bowman ES, Markand ON. The contribution of life events to pseudoseizure occurrence in adults. Bull Menninger Clin 1999;63:70-88.

40 Craig TJ. Life events: meanings and precursors. In: Halligan P, Bass C, Marshal JC, eds. Contemporary approaches to the study of hysteria. Oxford: Oxford University Press, 2001:88-101.

41 Ebel H, Steinmeyer E, Müller-Küppers M. Somatoform disorders: an empirical multidimensional diagnostic approach in psychopathology, personality and illness behavior. Neurol Psychiatry Brain Res 2001;9:127-32

42 Stone J, Zeman A, Sharpe M. Functional weakness and sensory disturbance. J Neurol Neurosurg Psychiatry 2002;73:241-5.

43 Lempert $\mathrm{T}$, Brandt $\mathrm{T}$, Dieterich $\mathrm{M}$, et al. How to identify psychogenic disorders of stance and gait. A video study in 37 patients. J Neurol 1991;238: 140-6.

44 Keane JR. Hysterical gait disorders. Neurology 1989;39:586-9.

45 Reuber M, Elger CE. Psychogenic nonepileptic seizures: review and update. Epilepsy Behav 2003:4:205-16

46 Cragar DE, Berry DTR, Fakhoury TA, et al. A review of diagnostic techniques in the differential diagnosis of epileptic and nonepileptic seizures. Neuropsychol Rev 2002;12:31-64.

47 Williams C, House AO. Heavy hospital case notes: a simple case finding method for psychiatric problems. Ir J Psychol Med 1999;16:123-6.

48 Bortz JJ, Prigatano GP, Blum D, et al. Differential response characteristics in nonepileptic and epileptic seizure patients on a test of verbal learning and memory. Neurology 1995;45:2029-34.

49 Brown MC, Levin BE, Ramsay RE, et al. Characteristics of patients with nonepileptic seizures. J Epilepsy 1991;4:225-9.

50 Meyer BU, Britton TC, Benecke R, et al. Motor responses evoked by magnetic brain stimulation in psychogenic limb weakness: diagnostic value and limitations. J Neurol 1992;239:251-5.

51 Howard JE, Dorfman $\amalg$. Evoked potentials in hysteria and malingering. J Clin Neurophysiol 1986;3:39-49.

52 Stone J, Sharpe M, Rothwell PM, et al. The 12-year prognosis of unilateral functional weakness and sensory disturbance. J Neurol Neurosurg Psychiatry 2003;74:591-6

53 Crimlisk HL, Bhatia K, Cope H, et al. Slater revisited: 6 year follow up study of patients with medically unexplained motor symptoms. $B M$ 1998;316:582-6.

54 Couprie W, Wijdicks EF, Rooijmans HG, et al. Outcome in conversion disorder: a follow up study. J Neurol Neurosurg Psychiatry 1995:58:750-2.

55 Nimnuan C, Hotopf $M$, Wessely S. Medically unexplained symptoms: how often and why are they missed? Q J Med 2000;93:28.

56 Reuber M, Fernández G, Bauer J, et al. Diagnostic delay in psychogenic nonepileptic seizures. Neurology 2002;58:493-5.

57 Kanner AM, Parra J, Frey M, et al. Psychiatric and neurologic predictors of psychogenic pseudoseizure outcome. Neurology 1999;53:933-8.

58 Mace CJ, Trimble MR. Ten-year prognosis of conversion disorder Br J Psychiatry 1996;169:282-8.

59 Gunatilake SB, De Silva HJ, Ranasinghe G. Twenty-seven venous cutdowns to treat pseudostatus epilepticus. Seizure 1997;6:71-2.

60 Smith PEM, Saunders J, Dawson A, et al. Intractable seizures in pregnancy. Lancet 1999;354:1522.

61 Reuber M, Baker GA, Gill R, et al. Failure to recognize psychogenic nonepileptic seizures may cause death. Neurology 2004;62:834-5.

62 Lipsitt DR. The factitious patient who sues. Am J Psychiatry 1986;143:1482.

63 Alsaadi TM, Thieman C, Shatzel A, et al. Video-EEG telemetry can be a crucial tool for neurologists experienced in epilepsy when diagnosing seizure disorders. Seizure 2004;13:32-4.

64 Glick TH. Suspected conversion disorder: foreseeable risks and avoidable errors. Acad Emerg Med 2000;7:1272-7.

65 Prashanth LK, Taly AB, Sinha S, et al. Wilson's disease: diagnostic errors and clinical implications. J Neurol Neurosurg Psychiatry 2004;75:907-9.

66 Tait RC, Chibnall JT. Physician judgements of chronic pain patients. Soc Sci Med 1997; 45:1199-205

67 Page LA, Wessely S. Medically unexplained symptoms: exacerbating factors in the doctor-patient encounter. $J R$ Soc Med 2003;96:223-7.

68 Gask L, Usherwood T. ABC or psychological medicine: the consultation. BMJ 2002;324:1567-9.

69 Aboukasm A, Mahr G, Gahry BR, et al. Retrospective analysis of the effects of psychotherapeutic interventions on outcomes of psychogenic nonepileptic seizures. Epilepsia 1998;39:470-3.

70 Shen W, Bowman ES, Markand ON. Presenting the diagnosis of pseudoseizure. Neurology 1990;40:756-9.

71 Creed F, Guthrie E. Techniques for interviewing somatising patients. Br J Psychiatry 1993;162:467-71 
72 Jackson J, Kroenke K. The effect of unmet expectations among adults presenting with physical symptoms. Ann Int Med 2001;134(suppl 9):889-97.

73 Goldberg D, Gask L, O'Dowd T. The treatment of somatization: teaching techniques of reattribution. J Psychosom Res 1989;33:689-95.

74 Parry G. NHS psychotherapy services in England-review of strategic policy. London: Department of Health, 1996.

75 Dale J, Tadros G, Adams S, et al. Do patients really want copies of their GP letters? A questionnaire survey of older adults and their carers. Psychiatr Bull 2004:28:200.

76 Katon W, Sullivan M, Walker E. Medical symptoms without identified pathology: relationship to psychiatric disorders, childhood and adult trauma, and personality traits. Ann Intern Med 2001;134(suppl 9):917-25.

77 Binzer M, Andersen PM, Kullgren G. Clinical characteristics of patients with motor disability due to conversion disorder: a prospective control group study. J Neurol Neurosurg Psychiatry 1997;63:83-5.

78 Van Hemert AM, Hengeveld MW, Bolk JH, et al. Psychiatric disorders in relation to medical illness among patients of a general medical out-patient clinic. Psychol Med 1993:23:167-73.

79 Henningsen P, Zimmermann T, Sattel H. Medically unexplained physical symptoms, anxiety and depression: a meta-analytic review. Psychosom Med 2004;65:528-33.

80 Reuber M, House AO, Pukrop R, et al. Somatization, dissociation and psychopathology in patients with psychogenic nonepileptic seizures. Epilepsy Res 2003;57:159-67.

81 Goldstein LH, Deale A, Mitchell-O'Malley S, et al. An evaluation of cognitive behavioral therapy as a treatment for dissociative seizures. Cogn Behav Neurol 2004;17:41-9.

82 Hiller W, Fichter MM, Rief W. A controlled treatment study of somatoform disorders including analysis of healthcare utilization and cost-effectiveness. J Psychosom Res 2003;54:369-80.

83 Allen LA, Escobar Jl, Lehrer PM, et al. Psychosocial treatments for multiple unexplained physical symptoms: a review of the literature. Psychosom Med 2002;64:939-50.

84 Kroenke K, Swindle R. Cognitive-behavioral therapy for somatization and symptom syndromes: a critical review of controlled clinical trials. Psychother Psychosom 2000;69:205-15.

85 Guthrie E. Psychotherapy of somatisation disorders. Curr Opin Psychiatry 1996;9:182-7.

86 Raine R, Haines A, Sensky T, et al. Systematic review of mental health interventions for patients with common somatic symptoms: can research evidence from secondary care be extrapolated to primary care? BMJ 1995;311:1328-32.

87 Bleichhardt G, Timmer B, Rief W. Cognitive behavioural therapy for patients with multiple somatoform symptoms: a randomized controlled trial in tertiary care. J Psychosom Res 2004;56:449-54.

88 Barsky AJ, Ahern D. Cognitive behavior therapy for hypochondriasis. JAMA 2004;291:1464-70.

89 Speckens AE, Van Hemert AM, Spinhoven P, et al. Cognitive behavioural therapy for medically unexplained physical symptoms: a randomised controlled trial. BMJ 1995;311:1328-32.

90 Creed F, Fernandes L, Guthrie E, et al. The cost-effectiveness of psychotherapy and paroxetine for severe irritable bowel syndrome. Gastroenterology 2003;124:303-17.

91 Guthrie E, Creed F, Dawson D, et al. A controlled trial of psychological treatment for irritable bowel syndrome. Gastroenterology 1991;100:450-7.

92 Whorwell PJ, Prior A, Faragher EB. Controlled trial of hypnotherapy in the treatment of severe irritable bowel syndrome. Lancet 1984; ii: 1232-4.

93 Reilly J, Baker GA, Rhodes J, et al. The association of sexual and physical abuse with somatization: characteristics of patients presenting with irritable bowel syndrome and non-epileptic attack disorder. Psychol Med 1999;29:399-406

94 Nanke A, Rief W. Biofeedback-based interventions in somatoform disorders: a randomized controlled trial. Acta Neuropsychiatr 2003;15:249-56.

95 Schilte AF, Portegiis PJ, Blankenstein AH, et al. Randomised controlled trial of disclosure of emotionally important events in somatisation in primary care. BMJ 2001;323:86.

96 Sharpe M, Peveler R, Mayou R. The psychological treatment of patients with functional somatic symptoms: a practical guide. J Psychosom Res 1992;36:515-29.

97 Roth A, Fonagy P. What works for whom. A critical review of psychotherapy research. New York: The Guildford Press, 1996.

98 O'Malley PG, Jackson JL, Santoro J, et al. Antidepressant therapy for unexplained symptoms and symptom syndromes. J Fam Pract 1999;48:980-90.

99 Soloff PH. Algorithms for pharmacological treatment of personality dimensions: symptom-specific treatments for cognitive-perceptual, affective, and impulsive-behavioral dysregulation. Bull Menninger Clin 1998;62:195-214.

100 Russo J, Katon W, Sullivan M, et al. Severity of somatization and its relationship to psychiatric disorder and personality. Psychol Med 1994; 1997:546-56.

101 Paykel ES, Tylee A, Wright A, et al. The Defeat of Depression Campaign: psychiatry in the public arena. Am J Psychiatry 1997;154(6 suppl):59-65.

102 Stone J, Durrance D, Wojcik W, et al. What do medical outpatients attending a neurology clinic think about antidepressants? J Psychosom Res 2003;56:293-5.

103 Soloff PH. Psychopharmacology of borderline personality disorder. Psychiatr Clin North Am 2000;23:169-92.

104 Binder LM, Salinsky MC, Smith SP. Psychological correlates of psychogenic seizures. J Clin Exp Neuropsychol 1994;16:524-30.

105 Kristensen O, Alving J. Pseudoseizures - risk factors and prognosis. A casecontrol study. Acta Neurol Scand 1992;85:177-80.

106 Fink P, Rosendal M, Toft T. Assessment and treatment of functional disorders in general practice: the extended reattribution and management model-an advanced educational program for nonpsychiatric doctors. Psychosomatics 2002;43:93-131.

107 Smith GR Jr, Monson RA, Ray DC. Psychiatric consultation in somatization disorder: a randomized controlled study. N Engl J Med 1986;314:1407-13.

108 Morriss R, Gask L, Ronalds C, et al. Clinical and patient satisfaction outcomes of a new treatment for somatized mental disorder taught to general practitioners. Br J Gen Pract 1999:263-7.

109 Binzer MD, Kullgren G. Motor conversion disorder, a prospective 2- to 5-year follow-up study. Psychosomatics 1998;39:519-27.

110 Carson AJ, Best K, Postma K, et al. The outcome of neurology outpatients with medically unexplained symptoms: a prospective cohort study. I Neurol Neurosurg Psychiatry 2003;74:897-900.

111 Reuber M, Pukrop R, Bauer J, et al. Outcome in psychogenic nonepileptic seizures: 1 to 10 year follow-up in 164 patients. Ann Neurol 2003;53:305-11.

112 Crimlisk HL, Bhatia KP, Cope $\mathrm{H}$, et al. Patterns of referral in patients with medically unexplained motor symptoms. J Psychosom Res 2000;49:217-9.

113 Coia $P$, Morley S. Medical reassurance and patients' responses. J Psychosom Res 1998;45:377-86.

114 Richardson RD, Engel CC. Evaluation and management of medically unexplained symptoms. Neurologist 2004;10:18-30.

115 House AO. The patient with unexplained medical symptoms: making the initial psychiatric contact. In: Mayou R, Bass C, Sharpe M, eds. Treatment of fictional somatic symptoms. Oxford: Oxford University Press, 1995:89-104. 